\title{
TENHO SEDE! VIVÊNCIA DO PACIENTE CIRÚRGICO NO PERÍODO PERIOPERATÓRIO
}

\author{
I am thirsty! Experience of the surgical patient in the perioperative period \\ Tengo sed! Vivencia del paciente quirúrgico en el periodo perioperatorio
} Larissa Cristina Jacovenco Rosa da Silva', Patricia Aroni², Lígia Fahl Fonseca ${ }^{3}$

RESUMO: Objetivo: Desvelar a vivência do paciente cirúrgico no pós-operatório imediato em relação à sede, na perspectiva da Teoria de Manejo de Sintomas. Método: Estudo qualitativo desenvolvido com 14 pacientes em hospital universitário de grande porte no Sul do Brasil. Para análise dos discursos, utilizou-se o método do Discurso do Sujeito Coletivo. Resultados: Emergiram quatro categorias: o corpo manifestando a sede, sentimentos vivenciados, utilizando mecanismos de enfrentamento e percebendo as estratégias de manejo da sede. Os sinais desse sintoma são angustiantes e extremamente estressores para quem os vivencia e a equipe multiprofissional envolvida não o valoriza. Conclusão: Sob a perspectiva da Teoria de Manejo de Sintomas, a sede, pela multivariedade do sintoma, é percebida e experienciada por meio de repercussões físicas e emocionais, refletindo sentimentos como angústia, medo e impotência diante do sintoma.

Palavras-chave: Sede. Assistência perioperatória. Enfermagem perioperatória. Cuidados de enfermagem.

ABSTRACT: Objective: To unveil the experience of the surgical patient in the immediate postoperative period regarding thirst, from the perspective of the Symptom Management Theory. Method: A qualitative study, undertaken with 14 patients in a large university hospital in southern Brazil. For discourse analysis, we used the Discourse of the Collective Subject method. Results: Four categories came up: the body manifesting thirst, experienced feelings, using coping mechanisms, and receiving thirst management strategies. Signs of this symptom are disturbing and extremely stressful for those experiencing them and the multidisciplinary team does not value them. Conclusions: From the perspective of the Symptom Management Theory, thirst, as a multivariate symptom, is perceived and experienced through physical and emotional repercussions, reflecting feelings of anguish, fear, and helplessness when facing the symptom.

Keywords: Thirst. Perioperative care. Perioperative nursing. Nursing care.

RESUMEN: Objetivo: desvelar la vivencia del paciente quirúrgico en el postoperatorio inmediato en relación a la sed, en la perspectiva de la Teoría de Manejo de Síntomas. Método: estudio cualitativo, desarrollado con 14 pacientes en hospital universitario de gran tamaño en el Sur de Brasil. Para el análisis de los discursos, se utilizó el método del Discurso del Sujeto Colectivo. Resultados: emergieron cuatro categorías: el cuerpo manifestando la sed, sentimientos vivenciados, utilizando mecanismos de enfrentamiento y percibiendo las estrategias de manejo de la sed. Las señales de ese síntoma son angustiantes y extremamente estresantes para quienes las vivencian y el equipo multiprofesional involucrado no las valoriza. Conclusiones: bajo la perspectiva de la Teoría de Manejo de Síntomas, la sed, por la multivariedad de síntomas, es percibida y experimentada por medio de repercusiones físicas y emocionales, reflejando sentimientos como angustia, miedo e impotencia ante los síntomas.

Palabras clave: Sed. Atención perioperativa. Enfermería perioperatoria. Atención de enfermería.

'Enfermeira; Especialista em Enfermagem Perioperatória pela Universidade Estadual de Londrina (UEL) - Londrina (PR), Brasil. E-mail: lari_jacovenco@hotmail.com ${ }^{2}$ Especialista em Enfermagem Perioperatória pela Universidade Estadual de Londrina (UEL); Professora Colaboradora do Departamento de Enfermagem da UEL - Londrina (PR), Brasil. E-mail:paty.aroni@ig.com.br Avenida Juscelino Kubitscheck, 235 - Jardim Brasil Senedese - CEP: 86130-000 - Bela Vista do Paraíso (PR), Brasil.

${ }^{3}$ Enfermeira; Doutora em Enfermagem; Professora Adjunta do departamento de Enfermagem da UEL - Londrina (PR), Brasil. E-mail: ligiafahl@gmail.com

Recebido: 05 maio 2016 - Aprovado: 22 jun. 2016

DOI: 10.5327/Z1414-4425201600020003 


\section{INTRODUÇÃO}

A sede no período perioperatório traz uma sensação tão premente de desconforto, que sobrepuja até mesmo a dor ou a fome, caracterizando-se como um sintoma por sua subjetividade. Não aplacada, apodera-se totalmente da consciência, aumentando ansiedade, desidratação, irritabilidade, fraqueza e desespero ${ }^{1,2}$.

Em pacientes submetidos a cirurgias, a sede é incidente e de alta intensidade, sobretudo no pós-operatório imediato (POI), quando ainda permanecem em jejum ${ }^{3,4}$. Diversos fatores desencadeiam a sede no paciente cirúrgico, como jejum, medicações e perdas sanguíneas ${ }^{5-7}$.

Semelhantemente à dor, a sede é uma sensação subjetiva, porém é um sintoma subvalorizado, submensurado, subtratado e não há protocolos para registro ou mensuração inseridos na prática clínica ${ }^{1,3,4}$. São escassos os estudos sobre o tema e não há sensibilização da equipe de saúde para se identificar e mensurar a sede ou a percepção do paciente que a experiencia.

A sede apresenta sinais identificáveis que alteram o funcionamento físico, mental e social do paciente ${ }^{1,8}$. A Teoria de Manejo de Sintomas permite compreender a multifatoriedade da sede na inter-relação de seus domínios - pessoa, ambiente, saúde/doença - e de suas dimensões - experiência, estratégia e repercussões do sintoma ${ }^{8,9}$.

Os pressupostos dessa teoria indicam que a deteç̧ão de sede no perioperatório baseia-se essencialmente no relato verbal do paciente. Além disso, o paciente cirúrgico faz parte de um grupo de alto risco para desenvolvimento da sede, abrindo caminho para o planejamento e a implementação de ações precoces para o seu manejo. A comunicação comprometida de alguns pacientes pode ser auxiliada pelo relato dos pais ou cuidadores, que são considerados fontes fidedignas de informações para intervenção do sintoma. A sede acarreta outros sintomas desconfortáveis - ou atributos - como lábios ressecados e saliva grossa, que também devem ser cuidados de forma integrada. Os domínios pessoa, ambiente e estado de saúde/doença afetam a percepção da sede, sua verbalização e reação às estratégias utilizadas para seu manejo ${ }^{8,9}$.

De acordo com a teoria, a experiência do sintoma está sujeita a múltiplos fatores individuais que interferem em seu surgimento e percepção. Observa-se que o paciente vivencia, avalia e enfrenta a sede de maneira particular ${ }^{9}$, especialmente pela interação dos variados elementos estressantes no perioperatório ${ }^{10}$. Importa que a equipe de saúde compreenda a fragilidade do paciente cirúrgico em seus momentos de tensão e instabilidade nessa jornada particular, com repercussões distintas para ele ${ }^{11}$.
Desejou-se conceder ao paciente cirúrgico, inserido em uma cultura institucional em que perde autonomia e voz, a possibilidade de expressar seus sentimentos e percepções sobre um sintoma tão incidente, perverso e, ao tempo, desvalorizado: a sede perioperatória. Compreender a vivência da sede no perioperatório é um desafio, o que nos leva a questionar como o paciente cirúrgico percebe, avalia e reage à experiência da sede nesse período.

Diante dessas questões, objetivou-se desvelar sentimentos, experiências e a percepção subjetiva do paciente cirúrgico em relação à sede no perioperatório, na perspectiva da Teoria de Manejo de Sintomas.

\section{MÉTODO}

Estudo qualitativo desenvolvido em um hospital universitário de grande porte no Sul do Brasil com pacientes no POI que apresentaram sede na Sala de Recuperação Anestésica (SRA), com intensidade maior que cinco, avaliados de acordo com a escala visual numérica de zero a dez.

Os critérios de participação foram: maiores de 18 anos e que estavam no pós-operatório internados em enfermarias. Os critérios de exclusão compreenderam os indivíduos que apresentavam dificuldades de comunicação oral e dor no momento da entrevista. Catorze pacientes foram abordados na enfermaria; as entrevistas, semiestruturadas, foram gravadas.

As perguntas norteadoras do estudo foram: "O senhor sentiu sede no perioperatório? Como foi sentir sede? Me fale mais sobre isso".

Analisaram-se os dados pelo método do Discurso do Sujeito Coletivo (DSC), utilizando-se da seleção de expressões-chave, ideias centrais e ancoragens que os organizou em um discurso sintetizador de pensamentos, representações, crenças e valores de uma população que vivencia experiências comuns $^{12}$. Os DSCs finais foram apresentados identificandose os sujeitos da pesquisa que compuseram o discurso por um código - letra $\mathrm{E}$ - seguido de um número.

Este trabalho obedeceu às diretrizes da Resolução/ CNS n ${ }^{\circ} 466$, de 2012, que regulamenta pesquisas com seres humanos, com aprovação do Comitê de Ética da instituição pesquisada (CAE n ${ }^{\circ}$ 02299412.6.0000.5231).

\section{RESULTADOS}

Os 14 entrevistados - 10 mulheres e 4 homens, com idade entre 23 e 67 anos - provinham das seguintes clínicas: ortopedia, 
ginecologia, neurocirurgia e cirurgia do trato digestivo. Na análise dos discursos, emergiram quatro categorias: "o corpo manifestando a sede"; "sentimentos vivenciados"; "utilizando mecanismos de enfrentamento"; "percebendo as estratégias de manejo da sede".

\section{0 corpo manifestando a sede}

Na primeira categoria, o paciente relatou, de forma intensa e marcante, as alterações corpóreas, relacionadas à sede, percebidas no período perioperatório. Boca seca, lábios secos e rachados, percepção de alteração na composição salivar e na textura da língua, sensação de sufocamento e fraqueza compõem um quadro de desconfortos prontamente identificado pelos pacientes:

Ah, parece que ressecou tudo, sabe? A boca seca e os lábios, parecia que iam rachar, língua meio grossa, tipo saburrosa. Não sei explicar. A saliva engrossa e fica com gosto ruim. Não tem uma saliva para engolir. Seu hálito, às vezes, muda, a saliva parece que muda de sabor, né... Eu acho que ela fica mais densa e mais amarga. Então percebi a garganta assim, seca. A gente fica meio sufocada, não tem líquido. Parece que nada escorrega, nenhuma saliva, nem nada. Meu corpo sentia vontade de água, fraco, parecia que estava secando. (E2, E3, E4, E6, E7, E9, E10, E11, E14)

O sinal mais identificado pelo paciente foi o ressecamento da cavidade oral, que afetou até sua fala:

Dá uma sensação ruim na boca; fica seca, difícil de engolir a saliva e até de falar, entende? Tinha dificuldade de falar, né, por estar com sede. Garganta seca, não conseguia nem falar direito, sem saliva na boca. Isso é ruim! (E1, E2, E5)

Fatores externos, como o ambiente, foram citados como potencializadores da sede:

Eu senti mais sede, não sei se é da dor ou do ar, que é bem forte no centro cirúrgico. Querendo ou não, a gente sempre fica deitado e um pouco com a boca aberta. (E7, E9, E13, E14)

Os pacientes relataram a ansiedade como fator desencadeante para a secura da cavidade oral, atributo intrinsecamente relacionado à sede:
Quando você está no pico de ansiedade, a boca seca, dispara o coração [...] Eu não sei explicar, parece que, quando eles optaram pelo jejum, eu fiquei com mais sede, talvez seja aquilo de você não poder beber, e aí você quer beber, entende? A ansiedade dá boca seca. Estava meio sonolenta, com a boca seca, aí fica: estou com sede, estou com sede! Daí você fica pensando e dá mais sede ainda. (E6, E7, E9)

Os pacientes fizeram analogias para retratar a magnitude da experiência e a intensidade do sintoma ${ }^{13}$, como ao descrever a sede, quando vasculharam seu universo vocabular para encontrar imagens relacionadas à sede experienciada:

\begin{abstract}
A boca seca... Vai grudando tudinho, parecendo que tem uma cola na boca, é essa sensação: uma cola na boca! Sabe quando a gente passa um dia sem escovar os dentes, daí fica aquela saliva grossa, com gosto ruim? É assim. Sabe quando a pressão fica baixa? É uma sensação parecida, mas só que com a boca. Quando você bebe dipirona, não tem aquele gostinho meio ruim? Vai ficando aquele gosto... Eu falava que eu estava virando camelo, que queria água, que precisava de água, que estava com muita sede! (E5, E7, E8, E12)
\end{abstract}

Os discursos evidenciaram que a experiência do jejum é desagradável, particularmente se por tempo mais prolongado. Nota-se, todavia, que a fome era mais suportável que a sede:

Fome não, fiquei bem tranquilo, mais de 24 horas sem comer, não senti fome alguma. Agora sede senti bastante, muita sede!!! Fome você aguenta, mas sede é complicado! A água, acho que é mais importante do que a fome. Primeiro a água. A água é... Nossa! (E1, E2, E7, E9, E10, E11, E14)

\section{Sentimentos vivenciados}

A segunda categoria compreende anseios e sensações relatados diante da experiência de sede. O paciente lembrou-se com frequência de experiências cirúrgicas anteriores em que também vivenciou sede:

Eu lembro! Na última cirurgia que eu tive, tive muita sede. Senti a mesma coisa [sede], uns sete anos atrás. Também falaram que tinha que ficar em jejum, e não tinha assim nem como molhar a boca. É ruim lembrar. (E6, E7, E8, E11) 
Os sentimentos resultantes da sede nesse período foram relatados enfaticamente como uma experiência angustiante:

É horrível, né, bastante ruim. É terrível ficar sem poder tomar água. Parece que tem alguma coisa dentro de você que vai te levando à loucura! Ai, vai dando aquela ansiedade de... Não pode, não pode, sabe? Nunca senti uma sede igual àquela. É ruim passar pela sede. Eu não desejo pra ninguém. (E1, E4, E5, E6, E7, E10, E12, E13)

A água foi citada como a primeira necessidade ao acordar da anestesia:

Do jeito que acordei da anestesia, já acordei com aquela sede, com aquela vontade de beber água. Até cheguei a pensar que, se não tomasse água naquela hora, parecia que ia morrer. (E3, E5, E6)

\section{Utilizando mecanismos de enfrentamento}

Para diminuir seu desconforto, os pacientes desenvolveram mecanismos para superação, como umedecer a cavidade oral com sua própria saliva:

Você está com sede e não pode beber água. Puxa saliva, água da garganta, você tenta achar qualquer coisa úmida pra você engolir. (E7, E8)

O sono se apresentou como uma tentativa de esquecimento do desconforto intenso: "Para eu esquecer que estava com sede ou fome eu dormia, mas não adiantava muito não" (E5).

O esforço de se concentrar em situações que não a sede foi uma forma de desviar a atenção do desconforto:

A única coisa que eu pensei foi que eu não posso tomar água, então não vou ficar aí pensando. Pensava no meu filho, e que logo iria passar toda aquela tensão. Eu estava muito ansiosa. (E6, E9)

O paciente assumiu, então, uma atitude de mutismo, ao perceber que não havia saída para o impasse do jejum: "Tem que ficar quieto, né, porque quer beber, tomar e comer, e não pode, né? Aí tem que ficar quieto" (E2).

Percebe-se que as experiências relativas à sede foram compartilhadas entre os pacientes na enfermaria, assim como as estratégias empíricas para manejo e diminuição de sua intensidade:
A sede? Eu fui esperta! Dessa vez eu molhei a boca e joguei a água fora. A menina ali do outro quarto, faz não sei quantos dias que ela não toma água, mas ela está fazendo isso. Ela falou: Molha a boca e joga a água fora. Eu falei: Oba!! É isso que eu vou fazer pra mim. Parece que nem escovando os dentes a secura melhora. Deu vontade de beber, mas não podia, daí joguei fora. Pelo menos não fica com a garganta seca. (E6, E7, E8, E12)

A busca pela água foi relatada como uma necessidade tão premente, que os pacientes foram levados a planejar ações que amenizassem a sede, mesmo que isso significasse quebrar protocolos estabelecidos:

Vixi!! Nem sei explicar pra você... Vinha aquela ansiedade e vi um moço passando com um litro de Coca-Cola e eu: Ai, moço, pelo amor de Deus, deixa eu beber? Vontade de pegar e tomar no bico, sabe? Insuportável! Não estava vendo a hora de tomar água. Você vê a água e pensa: Nossa, vou tomar um golinho escondido, mas daí não pode, né? Só sei que sem água não dá para ficar não. Já que tomei 10 comprimidos, falei: Vou descontar nos comprimidos, já que era um monte. Mas não era o suficiente para matar a sede. (E1, E2, E6, E7, E8, E9, E11, E10, E12)

\section{Percebendo as estratégias de manejo da sede}

A equipe de saúde raramente utilizou estratégias para cuidar do paciente cirúrgico com sede. Os relatos demonstraram, contudo, que suas atitudes denotaram incompreensão em relação aos sentimentos e às angústias geradas pela sede no perioperatório:

Hoje falei pra enfermeira: Mas não pode tomar nem um golinho de água? E ela: Não! A doutora disse: Vou fazer um soro pra você que sei que vai aliviar. O tempo todo eu falava que minha boca estava ressecada, mas diziam que, infelizmente, não poderiam dar água. Só queriam saber se eu estava com sede ou não. Pedi pra molhar minha boca, não pedi água. (E1, E8, E11, E12)

Eu falava: Por favor, então vê se vai fazer essa cirurgia logo, porque estou com bastante sede. Eu pedia, eu falava, pelo amor de Deus, vê que horas, que dia que vai fazer a cirurgia, se é hoje ou não, porque 
preciso tomar água. Falavam que não, que tinha que esperar, que tinha que ser forte, que eu tinha que aguentar. (E1, E5, E8, E14)

A sede repercutiu de forma negativa na experiência cirúrgica, pois já na fase pré-operatória os pacientes ansiaram por água e os profissionais envolvidos mostraram pouca preocupação em relação a isso. O estresse de sentir sede resultou em angústia e pressa para realizar a cirurgia. Na percepção dos pacientes, a equipe adotou estratégias nem sempre eficazes:

Infelizmente só molhavam a boca, assim ó [mostrando com os dedos nos lábios], para não ficar ressecada. Mas não acabava com a sede conforme eu queria, muito pelo contrário. Nossa!! Aquilo me deu vontade de beber mais água. A água era mais para voltar a umidade da boca. Não davam água, nem um pouquinho; pegavam algodão e passavam na boca. Mas só na boca também, e não davam água. Eu pedia: "Me dá água”, e vinham com aquele algodão. Foi muito ruim! Eu não via a hora de colocar água na boca. Mandavam ficar molhando a boca com um paninho, assim ó [levando a mão aos lábios], mas não resolve. Nossa! Dava vontade de comer o negócio! É horrível, nossa! (E1, E2, E4, E6, E7, E10, E11)

$\mathrm{Na}$ instituição onde se realizou esta pesquisa, fazia-se uso do Protocolo de Segurança para o Manejo da Sede (PSMS) e do picolé de gelo no $\mathrm{POI}^{14}$. Há relatos sobre esse novo manejo de cuidado, descrito como agradável e eficaz:

Deu o gelinho. Aí falei: Ai, que gelinho delicioso! Parecia que eu estava em uma banheira de gelo. O gelinho estava gostoso, fresquinho. Foi muito bom, bem refrescante. Parece que melhora todo aquele ressecado. Duas pedrinhas de gelo daquelas já foi o suficiente: ela deu uma, dali um pouco deu outra, daí acabou a sede! Senti saciada com o gelo. Sabe, melhorei. A saliva voltou a salivar normal, o lábio ficou pouco ressecado, quase acabou a sede. Tá aprovado! (E6, E7, E9, E13, E14)

\section{DISCUSSÃO}

A sede é uma experiência individual e subjetiva. De acordo com a Teoria de Manejo de Sintomas, a subjetividade da vivência é considerada na dimensão "Experiência do Sintoma" e reflete-se nas mudanças biopsicossociais, tanto nas sensações como na cognição de um indivíduo ${ }^{8,9}$. Os atributos relacionados à sede, como boca seca, apresentam alta correlação com a sua percepção ${ }^{15}$.

A sede atua como um balizador para a homeostase corpórea e, havendo alteração, o corpo percebe e sinaliza necessidade de água. $O$ paciente concentra sua atenção na mudança marcante em seu bem-estar provocada pela sede, descrevendo-a como um desconforto angustiante ${ }^{4,8}$ e proporcional à sua intensidade ${ }^{16}$. $\mathrm{O}$ fator tempo também impacta o significado que o indivíduo agrega a um sintoma desagradável; é como avalia sua experiência do sintoma e a resposta emocional que derivou dela ${ }^{10}$.

A experiência do sintoma reflete a variabilidade individual de quanto um mesmo estímulo influencia na intensidade de um desconforto ${ }^{10}$. O silêncio observado em pacientes no perioperatório pode sinalizar a presença de sede, quando gerada por seu componente periférico: a boca seca.

O ambiente cirúrgico climatizado e sentimentos recorrentemente vinculados ao período perioperatório, como dor e ansiedade, impõem-se como estressores específicos ao paciente, agravando-lhe a sede. A administração de oxigênio por períodos prolongados e a permanência da abertura da cavidade oral durante a entubação são fatores que a intensificam ${ }^{8}$.

A resposta a um sintoma inclui componentes fisiológicos, psicossociais, socioculturais e comportamentais, identificados de forma isolada ou em conjunto. Semelhantemente, reações fisiológicas à sede podem incluir alterações que acentuam o sintoma ${ }^{8,9}$, por exemplo, quanto maiores são o estresse e a tensão vivenciados pelos pacientes cirúrgicos, maiores são as dificuldades de enfrentamento e superação ${ }^{17}$. Os pacientes reconhecem a sede como consequência da ansiedade e dos temores perioperatórios e também a identificam como geradora de mais ansiedade, por não saberem se serão saciados. Cria-se, assim, um círculo vicioso, em que a ansiedade gera sede, que, por sua vez, gera mais ansiedade. Interromper esse processo é de fundamental importância para um cuidado humanizado.

De acordo com a Teoria de Manejo de Sintomas, as pessoas avaliam seus sintomas, julgam a causa, o tratamento e o efeito em sua vida ${ }^{9}$. O paciente perioperatório, ao reagir à percepção da sede, busca maneiras de explicar as alterações no seu funcionamento biofísico e nas suas sensações.

Respostas fisiológicas aos sintomas podem ativar reações negativas, o que acentua tais manifestações. Dessa forma, o paciente que experiencia a sede e a avalia como uma ameaça 
pode responder com um nível mais elevado de estresse, o que, por sua vez, reduz a ação das glândulas parótidas na lubrificação da cavidade oral, exacerbando a percepção geral de ameaça ${ }^{8,9}$.

Os pacientes fizeram uso de figuras de linguagem como "tubo de cola" e "camelo" - na tentativa de descrever a sede. As imagens são comparações simples e explícitas que o paciente efetuou entre o conceito-alvo - a sede - e uma imagem ou objeto que o representasse, conceituando-o pela descrição de suas similaridades. Fazemos isso quando nos defrontamos com novas situações e buscamos algo parecido para analisar e tentar compreender o novo objeto ${ }^{13}$.

O significado de um sintoma desagradável só pode ser conhecido pela descrição do indivíduo que o experiencia ${ }^{10}$. Para demonstrar a magnitude do sentimento ao relembrar a experiência da sede, o paciente recorreu à analogia ${ }^{13} \mathrm{com}$ a loucura, um distúrbio mental em que a pessoa afetada, não ciente de seu estado, tem o comportamento profundamente modificado, tornando-se irresponsável por seus atos. Semelhantemente, o paciente no perioperatório considerou a sede tão intensa e perturbadora, que fez até alusões a pensamentos de morte ${ }^{8}$. O desconforto da sede pode estar relacionado à sua intensidade, mas também é mediado por outras considerações, como o grau de atenção que o indivíduo confere ao sintoma ${ }^{10}$.

Conforme a Teoria de Manejo de Sintomas, sua avaliação compreende um complexo grupo de fatores que caracterizam a experiência. Neles estão incluídos intensidade, localização, frequência, natureza temporal e impacto afetivo. O paciente, ao avaliar a ameaça do sintoma, teve essa percepção de perigo envolvido ou de efeito nocivo'. Ao perceber a sede como ameaça, criou estratégias de enfrentamento para superá-la. As pessoas reagem de modo diferente diante de um estresse; assim, cada paciente adota um modo de enfrentamento ao experienciar a sede: mutismo, sono, mudança de pensamento e até tentativas de burlar o jejum ${ }^{8,17}$.

Segundo a Teoria de Manejo de Sintomas, podem-se direcionar estratégias de intervenção para um ou mais componentes individuais dos sintomas, a fim de alcançar um ou mais resultados ${ }^{9}$. A costumeira estratégia de simplesmente umidificar a cavidade oral, utilizando algodão embebido em água sob temperatura ambiente, instiga o paciente a querer mais água e não é suficiente para saciar sua sede ${ }^{18}$. Ademais, os pacientes alegam que o algodão molhado desperta uma sensação desagradável devido ao contato com sua textura.

Em uma cultura hospitalar na qual tanto o paciente como a equipe acreditam que a sede é um preço a se pagar para evitar complicações no processo cirúrgico, compreender o impacto que isso causa na perspectiva do paciente é extremamente relevante ${ }^{8}$. Os discursos refletem quão pouco a equipe valoriza, questiona e investiga a sede, demonstrando falta de empatia. A equipe desconhece avanços na identificação, mensuração, avaliação de segurança e utilização de estratégias eficazes para o manejo da sede no perioperatório. Sensibilizar os profissionais de saúde para que valorizem o sintoma sede configura-se, portanto, um grande desafio ${ }^{1,8}$.

Dentre esses avanços está o PSMS, um instrumento aplicado em pacientes cirúrgicos que apresentam sede na SRA. Visa à segurança no alívio da sede e avalia de forma sistematizada nível de consciência, presença de reflexos de proteção das vias aéreas e ausência de náuseas e vômitos; caso o paciente se encontre apto nessas categorias, recebe um picolé de gelo de $10 \mathrm{~mL}^{19}$. Em pequenos volumes, temperaturas baixas mostram-se mais eficazes para saciar a sede ${ }^{20}$.

Segundo a Teoria de Manejo de Sintomas, a dimensão percepção do sintoma contribui significativamente para o manejo adequado da sede. Contudo, ela engloba a interpretação da realidade, única para cada paciente, processada pelos sentidos e cuja informação é organizada, interpretada e transformada de modo dinâmico, intensificando ou modificando sua experiência ${ }^{8-10}$.

O manejo de um sintoma começa pela avaliação da experiência na perspectiva do paciente. Compreender esse fenômeno é fundamental para um eficaz planejamento de assistência e manejo. Os resultados deste estudo indicam que a percepção do paciente a respeito de sua sede impacta o modo como ele a avalia e reage a ela.

\section{CONCLUSÃO}

Este estudo evidenciou que o paciente cirúrgico percebe de forma intensa as repercussões físicas da sede, deflagrada por uma confluência de fatores. O paciente experiencia sentimentos desesperadores, chegando a fazer analogias com loucura e morte. O uso frequente de imagens que remetem ao significado de secura intensa e falta de água ilustra a força desses sentimentos.

A experiência da sede foi desvelada pelo relato das percepções do paciente cirúrgico, que atribuiu significados a ela segundo a avalia: um sintoma extremamente desagradável.

Esses resultados podem contribuir para a compreensão do significado da sede perioperatória, ao dar voz a quem a experiencia. Este é o primeiro passo para a valorização do sintoma sede visando subsidiar uma assistência humanizada e de qualidade aos pacientes no perioperatório. 


\section{REFERÊNCIAS}

1. Arai S, Stotts N, Puntillo K. Thirst in critically ill patients: from physiology to sensation. Am J Crit Care. [Internet]. 2013 [citado 5 jul. 2015];22(4):328-35. Disponível em: http://www.ncbi. nlm.nih. gov/pubmed/23817822

2. Gois CFL, Aguillar OM, Santos V, Rodríguez EOL. Stress factors for patients undergoing cardic surgery. Invest Educ Enferm [Internet]. 2012 [citado 6 jul. 2015];30(3):312-9. Disponível em: http://www. scielo.org.co/pdf/iee/v30n3/v30n3a 03.pdf

3. Aroni $P$, Nascimento LA, Fonseca LF. Avaliação de estratégias no manejo da sede na sala de recuperação pós-anestésica. Acta Paul Enferm [Internet]. 2012 [citado 19 jun. 2015];25(4):530-6. Disponível em: http://dx.doi.org/10.1590/S0103-21002012000 400008

4. Gois CFL, Dantas RA. Stressors in care at a thoracic surgery postoperative unit: nursing evaluation. Rev Latino-am Enferm [Internet]. 2004 [citado 20 jul. 2015];12(1):22-7. Disponível em: http:// dx.doi.org/10.1590/S0104-11692004000100004

5. Inenaga K, Ono K. Oral dryness and thirst: the central effect of acetylcholine on drinking behavior. J Oral Biosci [Internet]. 2010 [citado 2015 jul. 28];52(4):344-51. Disponível em: http://dx.doi.org/10.1016/ S1349-0079(10)80015-5

6. Lages N, Fonseca C, Neves A, Landeiro N, Abelha FJ. Náuseas e vômitos no pós-operatório: uma revisão do "pequeno-grande" problema. Rev Bras Anestesiol [Internet]. 2005 [citado 26 jun. 2015];55(5):575-85. Disponivel em: http://dx.doi.org/10.1590/S0034-7094200500 0500013

7. Pompeu DA, Rossi, LA. A administração de anestésicos voláteis como fator relacionado a náuseas e vômitos no período pós-operatório. Rev Gaúcha Enferm [Internet]. 2008 [citado 29 jul. 2015];29(1):1218. Disponível em: http://www.seer.ufrgs.br/RevistaGauchade enfermagem/article/viewFile/5309/3010

8. Conchon MFi, do Nascimento LA, Fonseca LF, Aroni P. Sede perioperatória: uma análise sob a perspectiva da Teoria de Manejo de Sintomas. Rev Esc Enferm USP [Internet]. 2015 [citado 1 ago. 2015]; 49(1):122-8. Disponível em: http://www.scielo.br/pdf/reeusp/ v49n1/pt_0080-6234-reeusp-49-01-0122.pdf

9. Dodd M, Janson S, Facione N, Faucett J, Froelicher ES, Humphreys $\mathrm{J}$, et al. Advancing the science of symptom management. J Adv Nurs [Internet]. 2001 [citado 20 jun. 2015];33(5):668-76. Disponível em: http://dx.doi.org/10.1046/j.1365-2648.2001.01697.x

10. Lenz ER, Pugh LC. Theory of Unpleasant Symtoms. In: Smith MJ, Liehr PR. Middle Range Theory for Nursing. New York: Springer Publishing Company; 2008. p. 159-82.

11. Chistóforo BEB, Zagonel IPS, Carvalho DS. Relacionamento enfermeiro-paciente no pré-operatório: uma reflexão à luz da teoria de Joyce Travelbee. Cogitare Enferm [Internet].
2006 [citado 20 jul. 2015];11(1):55-60. Disponível em: http:// www.faculdadespequenoprincipe.org.br/publicacoes/ arquivos/20080919050909_Artigo\%20relacionamento\%20 enfermeiro\%20paciente.pdf

12. Lefevre F, Lefevre AMC. Discurso do sujeito coletivo: representações sociais e intervenções comunicativas. Rev Texto Contexto Enferm [Internet]. 2014 [citado 20 jul. 2015];23(2):502-7. Disponível em: http:// www.scielo.br/pdf/tce/v23n2/pt_0104-0707-tce-23-02-00502.pdf

13. Goulart JAB. Analogias e metáforas no ensino de física: um exemplo em torno da temática de campos [dissertação]. [Internet]. Brasília: Universidade de Brasília; 2008 [citado 20 jul. 2015]. Disponível em: http://repositorio.unb.br/bitstream/10482/4854/1/2008_JaniceAnita BomfimGoulart.pdf

14. Conchon MF, Fonseca LF. Eficácia de gelo e água no manejo da sede no pós-operatório imediato: ensaio clínico randomizado. Rev Enferm UFPE [Internet]. 2014 [citado 1 ago. 2015];8(5):1435-40. Disponível em: http://www.revista.ufpe.br/revistaenfermagem/index.php/ revista/article /view/5839/pdf_5170

15. Stevenson RJ, Mahmut M, Rooney K. Individual differences in the interoceptive states of hunger, fullness and thirst. Appetite [Internet]. 2015 [citado 2015 jul. 26];95(1):44-57. Disponível em: http://www. sciencedirect.com/science/article/pii/s0195666315002950?np=y\#

16. Puntillo K, Arai SR, Cooper BA, Stotts NA, Nelson JE. A randomized clinical trial of an intervention to relieve thirst and dry mouth in intensive care unit patients. Intensive Care Med. [Internet]. 2014 [citado 26 jul. 2015];40(9):1295-302. Disponível em: http://www. ncbi.nlm.nih.gov/pmc/articles/PMC4149585/

17. Andolhe R, Guido LA, Bianchi ERF. Stress e coping no período perioperatório de câncer de mama. Rev Esc Enferm USP [Internet]. 2009 [citado 20 jul. 2015];43(3):711-20. Disponível em: http://dx.doi. org/10.1590/S0080-62342009000300030

18. Guest S, Essick G, Young M, Lee A, Phillips N, McGlone F. Oral hydration, parotid salivation and the perceived pleasantness of small water volumes. Physiol Behav [Internet]. 2006 [citado 20 jul. 2015];89(5):724-34. Disponível em: http://dx.doi.org/10.1016/j. physbeh.2006.08.012

19. Nascimento LA, Fonseca LF, Rosseto EG, Santos CB. Development of a safety protocol for management thirst in the immediate postoperative. Rev Esc Enferm USP [Internet]. 2014 [citado 1 ago. 2015];48(5):834-43 Disponível em: http://dx.doi.org/10.1590/ S0080- 6234201400005000009

20. Eccles R, Du-Plessis L, Dommels Y, Wilkinson JE. Cold pleasure: why we like ice drinks, ice-lollies and ice cream. Appetite [Internet]. 2013 [citado 20 jul. 2015];71:357-60. Disponível em: http://www. sciencedirect.com/science/article/pii/S0195666313003930 